Multiplicidades

(A) 


\title{
A DIFERENÇA E A ALTERIDADE
}

\section{Eurídice Figueiredo \\ $\mathrm{UFF} / \mathrm{CNPq}$}

\begin{abstract}
RESUMO
Este texto se propõe a discutir o pensamento diferencialista da crítica e da literatura norte-americanas presente no tratamento da alteridade em relação às representações dos mestiços e a mostrar que ele é diferente da lógica universalista brasileira. Muito se falou da ideologia do branqueamento no Brasil, que possibilita a passagem de uma cor/raça a outra, considerada superior. Este fenômeno, chamado de passing em inglês, em que os mulatos/mestiços claros podem ocultar sua origem, mudar de região e se fazer passar por brancos, também existe na América do Norte. Este tema - que aparece em vários romances - é altamente problemático nos dias de hoje, em que as minorias são instadas, pelo pensamento politicamente correto, a se assumir e lutar pelo direito à diferença. Esta visão nega ao personagem do mestiço-quase-branco o direito à singularidade e à construção de uma identidade individual(ista), já que ele deve se inserir sempre no âmbito de uma luta coletiva.
\end{abstract}

\section{PALAVRAS - CHAVE}

Representação do mestiço. Literatura do Canadá. Literatura dos Estados Unidos.

\begin{abstract}
A diferença como elemento desencadeador no estabelecimento da alteridade de uma pessoa ou de um grupo social banaliza-se de tal modo, na mídia e na indústria do entretenimento, que pensar seriamente sobre a questão torna-se uma tarefa bastante espinhosa por envolver os afetos, assunto cada vez mais estudado na América do Norte, onde, aliás, os debates sobre diferença e alteridade surgiram e se desenvolveram nas últimas décadas. Um exemplo desta vulgarização está no filme Hairspray (2007), ${ }^{1}$ comédia musical estrelada por John Travolta no papel de Edna Turnblad, a mãe gorda de Tracy Turnblad, a rechonchuda adolescente que quer ser dançarina do Corny Collins Show, um programa de um canal de televisão local. O conflito colocado - de uma pessoa que quer dançar mas não tem o physique du rôle para isso - não se sustentaria por mais de meia hora. Então, como o filme se passa em Baltimore, 1962, o roteiro lança mão da luta dos negros para desenrolar a trama: a adolescente gorda vai se juntar aos dançarinos negros, alijados da televisão pela gerente má, linda e loura, interpretada por Michelle Pfeiffer. Deste modo, o filme mistura um conflito de ordem pessoal, que eu diria insolúvel
\end{abstract}

${ }^{1}$ Direção de Adam Shankman, com roteiro de Leslie Dixon e John Waters (1988). 
(com o risco de ser politicamente incorreta, atingindo pessoas reais no campo dos afetos) - uma gorda pode até dançar bem mas não consegue se tornar bailarina/dançarina clássica - com a segregação racial nos Estados Unidos, este sim, um problema de ordem política, social, cultural e existencial para milhões de pessoas. Apesar da tendência atual que exige de nós cuidados especiais de linguagem e comportamento em relação a todo tipo de diferença, creio que as questões de alteridade realmente pertinentes para os estudos da literatura e da cultura são as que se referem às categorias de etnicidade (que englobam cor, raça e religião), de gênero (gender) e de sexualidade.

Janet M. Paterson, da Universidade de Toronto, no livro Figures de l'Autre dans le roman québécois (2004), apresenta um repertório de personagens "Outros" na literatura do Canadá Francês e do Quebec (1846-1999). Segundo sua pesquisa, as categorias de Outro designam: 1 . raças e nacionalidades; 2 . diversos; 3 . estrangeiro que chega na cidade; 4. identidade sexual; 5. religião; 6. saúde mental. ${ }^{2}$ Em livro recente, Figurações da alteridade (2007), que organizei com Maria Bernadette Porto, estendemos a perspectiva de Paterson para o universo do Canadá de língua inglesa, e tivemos a contribuição de 15 autores, do Canadá e do Brasil, que trataram de diversos "Outros". Na categoria de raça, nacionalidade ou etnicidade, aparecem as figuras do índio, do mestiço, dos imigrantes judeus, japoneses, negros, além de formas complexas de alteridade em que se misturam gênero (gender) com etnicidade, bastardia com ruptura, marginais de vários tipos (vagabundos, loucos, mendigos).

A base teórica em que Paterson se apoiou, e que também me serviu de lastro, foi o pensamento de Eric Landowski (2002), segundo o qual a sociedade majoritária, chamada de "grupo de referência", parece querer preservar sua integridade, imagem de um NÓS hipostasiado, criando diversas estratégias para se distinguir dos "diferentes", dos "Outros", sob uma aparência de não discriminação. Segundo Landowski, a sociedade majoritária pode exercer com seus Outros a exclusão ou a assimilação, mas em ambos os movimentos percebe-se o não reconhecimento da Alteridade pois ou se exclui (exclusão) ou transforma-se o Outro no Mesmo (assimilação). O reconhecimento só se daria na aceitação, pura e simples. A diferença que existe entre o grupo de referência e os outros não é de ordem ontológica porque, afinal, todos são homens; há, antes, diferenças posicionais, relacionais, em que se pode valorizar aspectos genéticos, dada cultura ou religião. Mas ela tende a converter-se, no plano empírico, numa série de oposições substanciais, porque algumas características são valorizadas, acentuadas. O grupo de referência fixa o inventário de traços diferenciais que servem para construir, diversificar e estabilizar o sistema das figuras do Outro. ${ }^{3}$ Para Landowski, a produção da diferença mobiliza dois planos: o referencial, em que a diferença se baseia em termos biológicos ou sociológicos, e o semiótico, em que a diferença passa a ser significante, ensejando a construção de um universo de sentido e de valores. Os traços diferenciais servem para significar figurativamente a diferença posicional que separa logicamente o Um de seu Outro, daí surgindo os estereótipos. Homi Bhabha explica o mecanismo da formação do estereótipo:

\footnotetext{
${ }^{2}$ http://www.chass.utoronto.ca/french/alterite

${ }^{3}$ LANDOWSKI. Presenças do Outro, p. 13.
} 
O estereótipo não é uma simplificação porque é uma falsa representação de uma dada realidade. É uma simplificação porque é uma forma presa, fixa, de representação que, ao negar o jogo da diferença (que a negação através do Outro permite), constitui um problema para a representação do sujeito em significações de relações psíquicas e sociais. ${ }^{4}$

A construção da diferença e dos discursos sobre a diferença e a alteridade varia segundo a história cultural de cada país. Assim, nos Estados Unidos e no Canadá existe uma percepção diferencialista - a valorização da diferença - que leva a considerar que uma gota de sangue negro ou indígena condena a pessoa a pertencer a um nível racial considerado inferior. Esta visão inviabiliza a existência do mestiço ou mulato; todos são negros ou indígenas. Nos movimentos que surgiram ao longo do século XX, como contestação ao racismo, que havia levado à segregação dos negros e ao quase extermínio dos índios, a mesma visão diferencialista vai prevalecer, pois os negros e indígenas na América do Norte foram formados neste contexto cultural.

Já no Brasil, o caldo cultural que engendrou o processo de mestiçagem, e seus discursos na construção da nação, filia-se a uma percepção universalista. Em princípio, todos têm a oportunidade de se embranquecer e ascender ao padrão considerado superior, ou ainda de se ver e se enquadrar na categoria que mais lhes agrade. Ora, desde os festejos do centenário da Abolição da Escravidão (1988), percebe-se uma crescente crítica ao discurso da mestiçagem e da democracia racial no Brasil, feita por parte de acadêmicos e ativistas ligados a movimentos negros, que substituíram o anti-racismo "universalista" pelo anti-racismo "diferencialista", por influência dos movimentos negros norte-americanos. ${ }^{5}$ Assim, o discurso da mestiçagem passa por um movimento que vai de mito de fundação nacional para ser encarado como um discurso ideológico que enaltece a fusão, em benefício do embranquecimento e da homogeneização, e que tem servido como base para uma política de exclusão social dos negros na sociedade brasileira. Gislene Aparecida dos Santos ${ }^{6}$ considera que Gilberto Freyre "inventa uma cultura da mestiçagem, uma apologia da mestiçagem, que pode ser valorizada ao se opor àquilo que é legitimamente negro", ou seja, o negro continuaria a desempenhar um papel subalterno. Kabengele Munanga, ${ }^{7}$ apesar de reconhecer a importância de Freyre por "ter mostrado que negros, índios e mestiços tiveram contribuições positivas na cultura brasileira", conclui que o mito da democracia racial "encobre os conflitos raciais", impedindo que os membros das comunidades não-brancas tomem consciência dos "sutis mecanismos de exclusão da qual são vítimas na sociedade". ${ }^{8}$ Segundo ele, o discurso da "mestiçagem como etapa transitória no processo de branqueamento constitui peça central da ideologia racial brasileira", e acrescenta que a população negra no Brasil representa, "do ponto de vista da elite 'pensante', uma ameaça ao futuro da raça e da civilização brancas no país". Para ele, o discurso da mestiçagem contém um "ideal implícito de

\footnotetext{
${ }^{4}$ BHABHA. O local da cultura, p. 117. (Grifo do autor).

${ }^{5}$ MUNANGA. Rediscutindo a mestiçagem no Brasil, p. 137.

${ }^{6}$ SANTOS. A invenção do ser negro, p. 160.

${ }^{7}$ MUNANGA. Rediscutindo a mestiçagem no Brasil, p. 88.

${ }^{8}$ MUNANGA. Rediscutindo a mestiçagem no Brasil, p. 89.
} 
homogeneidade" que não contempla a existência da população negra, o que o leva a falar de "etnocídio".

Para alguns, a categoria do mulato atrapalha a luta política. Eduardo de Oliveira e Oliveira tem um artigo com o sugestivo título de "O mulato, um obstáculo epistemológico". ${ }^{10}$ O norte-americano Michael Hanchard, em seu livro Orfeu e o poder, ${ }^{11}$ afirma que "isto [a existência do mulato] poderia explicar parcialmente as dificuldades da mobilização política e social conjunta dos negros e pardos", ${ }^{12}$ ou seja, o pardo não se junta à luta política dos negros porque se sente diferente.

Esta posição política racializada tem recebido muitas críticas. O cantor e compositor Caetano Veloso, em artigo publicado no New York Times (2000), afirma que a visão de Hanchard é uma simplificação da realidade brasileira que pode levar à "intolerância racial”. Os sociólogos franceses Pierre Bourdieu e Loïc Wacquant (1999) também atacaram o livro de Hanchard, criticando a influência imperialista norte-americana tanto nos estudos sobre questões etnoraciais do Brasil, levados a cabo por norteamericanos ou por intelectuais treinados nos Estados Unidos, quanto nos movimentos negros, o que estaria afetando a auto-imagem do Brasil. Em publicação recente, Yvonne Maggie, Peter Fry e outros (2007) se insurgiram contra a implantação de políticas públicas baseadas na raça. ${ }^{13} \mathrm{O}$ escritor João Ubaldo Ribeiro reforça esta posição contrária à importação de concepções dos Estados Unidos que põem em evidência o conflito e a separação entre raças, alertando para o fato de que esta política pode modificar a maneira como os brasileiros imaginam o país: de nação mestiça, que se orgulha disto, para nação de raças estanques, compartimentadas, segregadas. Apesar de ninguém negar a existência do racismo e a necessidade de combatê-lo, os opositores desta visão racializada defendem o fato de que o Brasil constitui exemplo único no mundo de uma mestiçagem plenamente realizada.

Vejo uma grande ironia na reivindicação racial da parte dos negros, porque a diferença humana baseada na "raça" foi inventada pelos europeus como forma de dominação. Mas acompanho o raciocínio de Kwame A. Appiah, segundo o qual as identidades, complexas e múltiplas, nascem de uma oposição a outras identidades, baseando-se em formações discursivas imaginárias e não na razão. ${ }^{14}$ No momento, parece oportuno para alguns adotar posições racializadas para lutar contra o racismo, mas este pode não ser o melhor caminho porque pode induzir a visões de gueto.

O mais irônico é que, nos Estados Unidos, a noção de mestiçagem começa a se infiltrar por influência da presença de vários tipos de imigrantes, inclusive dos hispânicos ou latinos que são, em sua maioria, mestiços e egressos de países cuja história cultural sempre incluiu a possibilidade de mestiçagem. O campeão de golfe Tiger Woods (nascido

\footnotetext{
${ }^{9}$ MUNANGA. Rediscutindo a mestiçagem no Brasil, p. 121.

${ }^{10}$ OLIVEIRA citado por MUNANGA. Rediscutindo a mestiçagem no Brasil, p. 16.

${ }^{11}$ A edição em inglês é de 1994, a tradução brasileira, de 2001.

${ }^{12}$ HANCHARD. Orfeu e o poder, p. 55. (Ênfase do autor).

${ }^{13}$ Não pretendo discutir, no âmbito deste artigo, questões de políticas públicas como a implantação de cotas nas universidades nem a gestão pública da saúde com ênfase na raça.

${ }^{14}$ APPIAH. Na casa de meu pai, p. 245.
} 
em 1975 na Califórnia), aparentemente negro - que deveria, portanto, se auto-declarar African American - desencadeou uma tendência ao se reivindicar como multirracial, já que a palavra "mestiço" não existe em inglês. Na Wikipédia em inglês, lê-se que Tiger Woods forjou uma palavra para se identificar racialmente: Cablinasian, a partir das iniciais das seguintes origens: Caucasian, Black, Indian, Asian. Seu pai, americano, teria 50\% de sangue africano, $25 \%$ chinês, $25 \%$ indígena; sua mãe, tailandesa, teria $50 \%$ de sangue tailandês, $25 \%$ chinês e $25 \%$ holandês. Tiger Woods, então, teria um quarto de sangue africano-americano, um quarto de chinês, um quarto de tailandês, um oitavo de holandês e um oitavo de indígena americano. Este percentual todo, feito nos Estados Unidos de hoje e veiculado pela internet, chega a ser paradoxal por seu anacronismo, pois remete às classificações coloniais da América Latina e do Caribe, com seus quarteirões e oitavões. ${ }^{15}$

Ao estudar as representações dos mestiços na literatura, percebi como minha percepção da etnicidade se distinguia da encontrada nos textos críticos canônicos produzidos na América do Norte. Como ousar discordar de atitudes tão politicamente corretas e tão estabelecidas quando eu estava escrevendo a partir de fora? Ao atravessar fronteiras por um olhar excêntrico e descentrado, ao negociar esta defasagem, creio ter-me aproximado daquilo que Reed Way Dasenbrock chamou de "hermenêutica da diferença", "que permite entender textos diferentes de nós e entendê-los por serem diferentes de nós". ${ }^{16}$ Como cada um fala a partir de seu lugar de enunciação, seu olhar crítico é determinado pela visão de mundo de sua cultura. Estou consciente, portanto, de que minha visão é influenciada pelo modo de pensar a questão no Brasil, país fortemente marcado pela lógica da mestiçagem.

Muito se falou da ideologia do branqueamento no Brasil, que possibilita a passagem de uma cor/raça a outra, considerada superior. Este fenômeno, chamado de passing em inglês, em que os mulatos/mestiços claros podem ocultar sua origem, mudar de região e se fazer passar por brancos, também existe na América do Norte. Este tópos está presente na literatura dos Estados Unidos, desde as dime novels, textos de cunho popular que inspiraram os filmes do gênero western até na alta literatura, como em William Faulkner (1897-1962).

No universo criado por Faulkner, pode-se depreender uma verdadeira maldição trágica que pesa sobre as pessoas, enredando-as de tal modo que elas não vislumbram nenhuma salvação possível. Em Absalão, Absalão! Thomas Sutpen se divorcia de Eulalia Bon, com quem se casara no Haiti, porque descobre ou desconfia que ela tem sangue

\footnotetext{
${ }^{15} \mathrm{Na}$ França, o Abbé Prévost cita um repertório de combinações possíveis: "Le Métif vient d'un Espagnol \& d'une Indienne; le Castis, ou le Terceron, d'un Métif \& d'une Métive; le Quarteron, d'un Noir \& d'une Espagnole; le Mulâtre, d'une femme noire \& d'un blanc; le Grifo, d'une Noire \& d'un Mulâtre; le Sambo, d'un Mulâtre \& d'un Indien; \& le Cabro, d'une Indienne et d'un Sambo." (Citado por ALBERTANCOPPOLA. La notion de métissage à travers les dictionnaires du XVIIIème siècle, p. 40). No Brasil, Gilberto Freyre evoca uma tabuada das misturas para ficar branco, retirada do livro de Raymundo José de Souza Gayoso [1818]: "Tabuada das misturas para ficar branco/1 branco com uma negra produz mulato/Metade branco, metade preto./1 branco com uma mulata produz quartão/Trez quartos branco, e um quarto negro./1 branco com um quartão produz outão/7/8 branco e 1/8 negro./1 branco com uma outona produz branco/ Inteiramente branco" (SOUZA citado por FREYRE. Sobrados e mucambos, p. 778). ${ }^{16}$ DASENBROCK citado por EIGENBROD. Travelling Knowledges, p. xiii.
} 
negro. Ele se recusa a ter contato com o filho deles, Charles Bon que, na universidade, acaba se tornando amigo de seu filho Henry, e noivo/amante de sua filha Judith. Thomas Sutpen diz ao seu filho: "Ele não deve se casar com ela, Henry. O pai da mãe dele me disse que a mulher era uma espanhola. Eu acreditei nele, mas só depois que ele nasceu eu descobri que a mãe dele tinha uma parte de sangue negro." ${ }^{17}$ Deste raciocínio se conclui que o horror ao incesto é menor do que o horror ao casamento com um negro, como percebe Charles: "Então é a miscigenação, e não o incesto, que você não pode suportar." 18

Em outro romance de Faulkner, Luz em agosto, Eupheus [Doc] Hines, um louco fanático, racista e moralista, que usa uma linguagem religiosa belicosa e maniqueísta, atribui sangue negro ao amante da filha, que ele não conhece. Apesar de todos dizerem que ele é mexicano, o personagem mata o amante, deixa a filha morrer durante o parto, entrega a criança a um orfanato, lá permanecendo como porteiro durante 5 anos, tempo suficiente para dizer a todos que a criança é negra. Assim, Joe Christmas, o neto do velho Doc Hines, vai viver e morrer como negro, embora tivesse a aparência de um branco. Ele poderia ter feito o passing mas a maldição era mais forte, ele crescera na convicção de que era negro e é isto que vai dizer para as pessoas. Com efeito, a questão da cor nos Estados Unidos se define mais pela palavra proferida do que pela aparência: se um indivíduo parece branco, mas alguém o acusa de ser negro, ele será visto como tal.

Em A marca humana (2002) [no original, de 2000, The Human Stain], Philip Roth retrata com muita ironia o percurso do professor Coleman Silk que, originário de uma família negra de Nova Jersey, decide, aos 20 anos, se fazer passar por branco e adotar a identidade de judeu e que, aos 70 anos, depois de uma carreira brilhante, é levado a demitir-se, humilhado, devido às acusações de racismo feitas por dois alunos negros, sempre ausentes às suas aulas, que ele chama de spooks (o sentido principal é de fantasmas mas o termo foi usado no passado como termo pejorativo para designar os negros). De maneira não linear vai-se montando o quebra-cabeças que foi a vida do personagem que, aos 17 anos, para satisfazer o sonho de seu pai, vai estudar na Howard University, uma tradicional universidade para negros, em Washington D.C., onde descobrirá uma face mais violenta do racismo. "Recusaram-se a lhe servir um cachorro-quente na Woolsworth's no centro de Washington, e ainda por cima o chamaram de crioulo." 19 Tendo odiado tanto a cidade quanto a universidade, Coleman abandona a Howard University porque ele se recusa a adotar qualquer tipo de identidade coletiva, nem em forma de auto-defesa nem de ataque, ele reivindica, ao contrário, sua singularidade, seu direito de viver o seu mundo interior secreto, oculto, privado.

Na Howard, Coleman não descobriu apenas que era um crioulo em Washington, D.C. como se esse choque não bastasse, descobriu também que era negro. Não só isso, mas também que era um negro da Howard. Da noite para o dia, o eu nu e cru fazia parte de um nós com toda a solidez arrogante do nós, e Coleman não queria nenhuma relação com

\footnotetext{
${ }^{17}$ FAULKNER. Absalão, Absalão!, p. 320.

${ }^{18}$ FAULKNER. Absalão, Absalão!, p. 321.

${ }^{19}$ ROTH. A marca humana, p. 135.
} 
aquele nós, nem com nenhum outro nós opressor que viesse a aparecer. [...] Não, jamais a tirania do nós, sempre louco para tragá-lo, aquele nós moral coercitivo, abrangente, histórico, inevitável, com seu insidioso E pluribus unum. Nem o eles da Woolsworth's nem o nós da Howard. Em vez disso, o eu nu e cru, com toda a sua agilidade. ${ }^{20}$

Nesta passagem, pode-se perceber que Coleman Silk quer preservar sua individualidade, recusando-se a fazer parte de qualquer coletividade. Um branco pode fazê-lo, um negro, não. Assim, ao se alistar na Marinha, ele decide que será, a partir dali, um branco, o que significa que ele terá de eliminar a família de seu convívio. Em compensação, ele será livre e não terá de suportar as humilhações, os obstáculos e as imposições que sua família sempre teve de suportar. Ao mudar de cor, ele elimina os sentimentos que provocavam seu sofrimento: "A mágoa, a dor, o fingimento, a vergonha - todas as agonias interiores do fracasso e da derrota. Em vez disso, livre no palco maior. Livre para seguir adiante e ser magnífico. Livre para representar o drama ilimitado e autodefinidor dos pronomes nós, eles e eu." ${ }^{21}$ Ele paga caro por esta liberdade. Como teria de dizer à esposa que seus pais morreram e que não teve irmãos, antes mesmo de se casar ele teve de explicar tudo à sua mãe e aos seus irmãos, numa cena surdamente violenta, brutal. Simbolicamente, ele assassina a mãe. Ao longo de sua vida, a única pessoa com quem ele mantém algum contato é sua irmã Ernestine, que lhe dá notícias da mãe e da família e que compreende sua decisão. $O$ texto sugere o peso que representou para ele este segredo, no plano dos afetos, inclusive com o medo de ter filhos negros. A cada gravidez - e foram três, sendo que da última sua esposa teve gêmeos - o pânico.

Como em A marca humana, o romance In Search of April Raintree, de Beatrice Culleton Mosionier, também cria um personagem mestiço-quase-branco que quer viver sua singularidade sem ter de se assumir como ser coletivo, os Métis do Canadá. Os autóctones constituem um fantasma no imaginário dos canadenses na medida em que sua presença na formação da nação foi recalcada. Nas últimas décadas, há uma proliferação de romances que tratam do assunto: assiste-se, assim, à volta do recalcado, que parece estar sendo trabalhado no inconsciente coletivo e que se manifesta de maneira muito sugestiva na produção literária do país. Nestes romances, percebem-se a marginalidade de Índios ${ }^{22}$ e Métis, ${ }^{23}$ o racismo, a violência da sociedade que os envia de volta ao mundo dos "selvagens" e a não aceitação da mestiçagem, concebida como uma "ambivalência identitária insolúvel", ${ }^{24}$ que parece constituir uma espécie de ameaça ao bom funcionamento da ordem pública.

\footnotetext{
${ }^{20}$ ROTH. A marca humana, p. 142. (Grifos do autor.)

${ }^{21}$ ROTH. A marca humana, p. 143. (Grifos do autor.)

${ }^{22}$ Apesar de no Canadá se preferir usar os termos Ameríndios e Primeiras Nações para designar os povos autóctones, optei por empregar os termos mais comuns no Brasil.

${ }^{23}$ Os Métis formam um grupo étnico, reconhecido pela Constituição de 1982 (seção 35) como um povo autóctone, juntamente com os Indígenas e os Inuit. De acordo com o censo de 2001, os Métis constituem 30\% da população autóctone, ou seja, 292.310 Métis num universo de 976.305 aborígines. Só será usado o termo Métis (com maiúscula) para designar a nação ou os membros da nação; nos demais casos, será usado o termo português mestiço.

${ }^{24}$ THÉRIEN. Le Métis comme horizon de la disparition, p. 130.
} 
O meu argumento é que a produção da diferença em relação ao autóctone no Canadá foi construída ao longo da história nos dois planos, o referencial e o semiótico. Apesar das mudanças significativas ocorridas nos últimos anos, em termos políticos e culturais, com a assinatura de tratados com algumas nações, a criação de museus, bibliotecas, o aparecimento de obras escritas por escritores autóctones, sua presença no espaço público ainda é rarefeita. Em termos imaginários - que é o mundo da ficção - as estratégias narrativas usadas para tecer as tramas induzem a sua exclusão da sociedade. Os recursos literários usados para que o personagem "assuma" sua identidade autóctone podem ser de ordem mítica, ritual, identitária, mas resulta sempre que, ao fim da narrativa, o personagem do índio ou do Métis é levado a ir morar junto a seu "povo", em seus territórios, não permanecendo nem se misturando com o grupo majoritário branco. Assim, apesar de personagens mestiços terem cada vez mais voz nos romances, eles ainda não parecem "normais" no espaço público, sua alteridade ainda parece radical demais.

Assim, os mestiços que aparecem como personagens dos romances que li e analisei nos últimos anos, mesmo os mais brancos - quer pelo aspecto físico, quer pela educação - são expulsos da pólis, como o bode expiatório, em benefício da homogeneidade da sociedade branca. A doxa exige que eles façam a coisa certa, ou seja, optem por seu "verdadeiro" povo, em nome de uma necessidade ontológica e política. Trata-se de uma forma de segregação que não ousa dizer seu nome e que, curiosamente, se repete em praticamente todos os romances pesquisados, inclusive no de Beatrice Culleton Mosionier, que é uma escritora de origem mestiça (Métis), criada e educada (como sua protagonista) em lares adotivos de brancos e escolas públicas freqüentadas por brancos. Não chega a surpreender o fato de seu imaginário não se distinguir do de outros escritores "brancos", pois o imaginário não tem "raça". Frantz Fanon considerava que os jovens antilhanos (negros) possuíam o mesmo inconsciente coletivo que os franceses, justamente por terem a mesma educação e a mesma formação que eles, expostos que eram aos mesmos filmes, mesmos gibis, e aos mesmos clichês sobre os negros. Ele define o inconsciente coletivo como "o conjunto de preconceitos, mitos, atitudes coletivas de um grupo determinado". 25

Neste romance de base autobiográfica, a ênfase é colocada nas duas irmãs, April e Cheryl: ambas são bonitas, espertas e estudiosas; a diferença principal que as separa é a cor da pele. April é bem clara, enquanto a irmã é morena, representando bem o tipo indígena. A aparência vai corresponder também às posições ideológicas em relação à ancestralidade: Cheryl desde pequena se identifica com o povo Métis, com a história da luta de Louis Riel (que ela estuda com afinco) contra a posição da escola e dos professores; enquanto April prefere se distanciar ou mesmo renegar esta identidade. Na verdade, as duas meninas não tiveram quase nenhum acesso à cultura da nação Métis, pois, quando elas ainda eram pequenas, os pais deixaram a comunidade de Norway House, em que viviam, e foram se estabelecer na cidade de Winnipeg para se tratarem de tuberculose.

Crescendo num mundo que denigre os índios e mestiços, April vai querer se distanciar de sua identidade de Métis para se tornar uma pessoa comum, anônima, tão

${ }^{25}$ FANON. Peau noire masques blancs, p. 152. 
branca quanto a maioria, a fim de não sofrer nem as conseqüências do racismo nem as possíveis taras impingidas aos autóctones como a "síndrome da mulher indígena", explicada pela assistente social: ela começa com atitudes de contestação que acabam desembocando em gravidez precoce, alcoolismo, uso de drogas, prostituição e prisão. ${ }^{26}$ Ela só se esqueceu de dizer que o desenlace deste itinerário era o suicídio, que é justamente o caminho trilhado por Cheryl, e que evoca também o percurso das duas irmãs da autora.

O racismo da sociedade canadense está presente em todas as etapas da vida das protagonistas, que vão usar estratégias de sobrevivência diferentes: Cheryl reivindica a identidade mestiça, milita pela causa, parece estar bem adaptada neste papel ativo e combativo. No entanto, depois de um período em que April não mantém contato com ela por estar morando em Toronto, e durante o qual o leitor também desconhece o que está acontecendo, Cheryl sai dos trilhos, desmorona. O suicídio é uma solução final, já que sua vida estava destroçada e que ela era incapaz de cuidar de seu próprio bebê, cuja existência April desconhecia.

No final do romance, April adota o sobrinho e passa a reivindicar sua pertença ao povo Métis. "As I stared at Henry Lee, I remembered that during the night I had used the words MY PEOPLE, OUR PEOPLE and meant them. The denial had been lifted from my spirit. It was tragic that it had taken Cheryl's death to bring me to accept my identity." ${ }^{27}$ No entanto, esta cena, tão elogiada pela crítica canadense, parece-me paradoxal: com qual povo, com qual cultura ela vai-se identificar, se não conhece nada sobre os Métis senão o desprezo e o ódio da maioria branca com a qual ela sempre conviveu?

Esta conversão final, em que April cumpre sua obrigação de "voltar" para os seus, me parece problemática. Margery Fee afirma não estar muito convencida da capacidade de April de educar o menino como um Métis comprometido com a causa - a committed Métis activist. ${ }^{28}$ Minha questão seria diferente da que coloca Fee: por que o garoto deve ser um militante da causa Métis? Por que as minorias étnicas têm de ser defensoras da raça e a maioria branca pode realizar projetos meramente individuais e individualistas? Por que April não tinha o direito de viver seu projeto individual enquanto "branca" (na aparência)? Margery Fee explica que só a maioria pode exercer a liberdade de fazer escolhas e trilhar os caminhos que quiser ao observar: "A liberdade de escolher a identidade ou mover-se numa série de identificações é normalmente reservada à maioria, ao passo que membros das minorias têm identidades - negativas - impostas a eles em graus variados de brutalidade." ${ }^{29}$ Sendo politicamente correta, Fee considera que cada membro de uma minoria que abandona o grupo contribui para o desaparecimento das tradições. Assim, "a identidade para os povos indígenas não é uma decisão pessoal e a comunidade deixa claro que os indivíduos são responsáveis pela sobrevivência do grupo". ${ }^{30}$

\footnotetext{
${ }^{26}$ MOSIONIER. In Search of April Raintree, p. 62.

${ }^{27}$ MOSIONIER. In Search of April Raintree, p. 207.

${ }^{28}$ FEE. Deploying Identity in the Face of Racism, p. 224.

${ }^{29}$ FEE. Deploying Identity in the Face of Racism, p. 212.

${ }^{30}$ FEE. Deploying Identity in the Face of Racism, p. 216.
} 
Entretanto, acredito que o binarismo que opõe, de um lado o índio alcoólatra, de outro o índio ativista, é inaceitável para April, que não quer nem sofrer da "síndrome da mulher indígena", nem tornar-se militante de nenhuma causa. Assim, a exigência de assumir a sua "raça", que a sociedade lhe impõe, aparece no final do romance de um modo fortuito e forçado.

Margery Fee atribui a responsabilidade do suicídio de Cheryl à traição e ao abandono de April. Parece-me excessivamente dicotômica esta oposição entre as duas irmãs, que faz recair toda a culpa sobre April, a traidora da raça, que tinha a obrigação ontológica de ser Métis e que, ao final, recebe o sobrinho como uma espécie de prêmio. Fee considera injusto que ela receba a criança, que autóctones nasçam com pele clara e possam usufruir de privilégios que não lhes pertencem. ${ }^{31}$ A posição de Fee é claramente em defesa dos aborígines, e sua intenção é a melhor possível, dentro da lógica identitária canadense, em que cada grupo étnico deve se "assumir". Entretanto, dentro da lógica brasileira da mestiçagem, não há nenhuma razão para culpar uma personagem pelas tramas aleatórias da genética, nem para se exigir dela que se fixe em identidades imutáveis.

Em grande parte das obras que tematizam esta questão, o mestiço-quase-branco é desmascarado quando quer se casar com uma pessoa branca, sendo, então, eliminado do contato da sociedade como uma espécie de bode expiatório. Este tema é altamente problemático nos dias de hoje, em que as minorias são instadas, pelo pensamento politicamente correto, a se assumir e lutar pelo direito à diferença. Esta visão nega ao personagem do mestiço-quase-branco o direito à singularidade e à construção de uma identidade individual(ista), já que ele deve se inserir sempre no âmbito de uma luta coletiva.

A idéia da mestiçagem e do branqueamento, presente no passing, é muito incômoda na sociedade norte-americana, o que é perceptível no cinema de massa, que raramente mostra cenas amorosas de casais mistos e o nascimento de mestiços. Na adaptação cinematográfica de A marca humana, ${ }^{32}$ a questão da mudança de cor de Coleman Silk foi negligenciada. De modo semelhante, o filme de animação Pocahontas, ${ }^{33}$ destinado ao público infantil, apesar de ser baseado em fatos verdadeiros, termina com a separação do interétnico, quando a verdade histórica é que a índia Pocahontas se casou com o capitão inglês John Smith e o casal teve um filho. A rasura é um claro sinal de que se trata de algo que se denega e se busca obliterar. Assim, o cinema e a indústria do entretenimento mostram formas de alteridade inócuas - como a da gordinha em Hairspray - e rasuram aquelas que põem em xeque valores fortemente enraizados na sociedade norte-americana.

\section{A}

\footnotetext{
${ }^{31}$ FEE. Deploying Identity in the Face of Racism, p. 224.

${ }^{32}$ Filme de 2003, dirigido por Robert Benton, com roteiro de Nicholas Meyer, a partir do romance de Philip Roth. Anthony Hopkins interpreta Coleman Silk.

${ }^{33}$ Filme de 1995, dirigido por Mike Gabriel e Eric Goldberg, a partir do roteiro de Carl Binder e Chris Buck.
} 


\section{RÉ S U MÉ}

Ce texte se propose à discuter la pensée différencialiste, présente dans la critique et la littérature nord-américaines, laquelle se manifeste dans le traitement de l'altérité des Métis et à démontrer ainsi qu'elle se distingue de la logique universaliste brésilienne. On a beaucoup écrit sur l'idéologie du blanchiment au Brésil, qui rend possible le passage d'une couleur/race à l'autre, considérée supérieure. Ce phénomène, dénommé passing en anglais, par lequel les mulâtres/métis clairs de peau peuvent cacher leur origine, changer de région et se faire passer pour blancs, existe aussi en Amérique du Nord. Ce thème - qui apparaît dans plusieurs romans - est très problématique de nos jours, quand les minorités sont amenées par la pensée de la correction politique à s'assumer et à lutter en faveur du droit à la différence. Cette vision dénie au personnage du métis-presque-blanc le droit à la singularité et à la construction d'une identité individuelle/individualiste puisqu'il doit s'insérer toujours dans le cadre d'une lutte collective.

\section{MOTS - CLÉ S}

Représentation du Métis. Littérature du Canada. Littérature des Etats-Unis.

\section{REFERÊNCIAS}

ALBERTAN-COPPOLA, Sylviane. La notion de métissage à travers les dictionnaires du XVIIIème siècle. In: MARIMOUTOU, Jean-Claude Carpanin; RACAULT, JeanMichel (Ed.). Métissages. Paris: L'Harmattan, 1992.

APPIAH, Kwame Anthony. Na casa de meu pai: a África na filosofia da cultura. Rio de Janeiro: Contraponto, 1997.

BHABHA, Homi. O local da cultura. Trad. Myriam Ávila; Eliana Lourenço de Lima Reis; Gláucia Renate Gonçalves. Belo Horizonte: Ed. UFMG, 1998.

BOURDIEU, Pierre; WACQUANT, Loïc. On the Cunning of Imperialism Reason. Theory, Culture \& Society, SAGE, London, v. 16(1), p. 41-58, 1999.

EIGENBROD, Renate. Travelling Knowledges. Positioning the Im/Migrant Reader of Aboriginal Literatures in Canada. Winnipeg: University of Manitoba Press, 2005.

FANON, Frantz. Peau noire masques blancs. Paris: Seuil, 1952.

FAUlKNER, William. Absalão, Absalão! Trad. Sônia Régis. Rio de Janeiro: Nova Fronteira, 1981.

FAULKNER, William. Luz em agosto. Trad. Celso Mauro Paciornik. São Paulo: Cosac Naify, 2007.

FEE, Margery. Deploying Identity in the Face of Racism. In: MOSIONIER, Beatrice Culleton. In Search of April Raintree. Critical Edition edited by Cheryl Suzack. Winnipeg (Canada): Portage \& Main Press, 1999. 
FIGUEIREDO, Eurídice. Os discursos da mestiçagem: interseções com outros discursos, críticas, ressemantizações. Revista Gragoatá, Niterói: Programa de Pós-Graduação em Letras/EdUFF, n. 22, 2. semestre 2007.

FIGUEIREDO, Eurídice; PORTO, Maria Bernadette Velloso. Figurações da alteridade. Niterói: EdUFF/ABECAN, 2007.

FOSTER, John E. The Plains Metis. In: MORRISON, R. Bruce; WILSON, C. Roderick (Ed.). Native peoples. The Canadian Experience. Toronto: Oxford University Press, 2004. p. 297-319.

FREYRE, Gilberto. Sobrados e mucambos: decadência do patriarcado rural e desenvolvimento do urbano. São Paulo: Global, 2003.

FRY, Peter. A persistência das raças: ensaios antropológicos sobre o Brasil e a África Austral. São Paulo: Civilização Brasileira, 2005.

FRY, Peter et al. (Org.). Divisões perigosas: políticas raciais no Brasil contemporâneo. Rio de Janeiro: Civilização Brasileira, 2007.

HANCHARD, Michael. Orfeu e o poder: movimento negro no Rio de Janeiro e São Paulo (1945-1988). Rio de Janeiro: Ed. UERJ, 2001.

HANCHARD, Michael. Acts of Misrecognition: Transnational Black Politics, AntiImperialism and the Ethnocentrisms of Pierre Bourdieu and Loïc Wacquant. Theory, Culture \& Society, SAGE, London, v. 20(4), p. 5-29, 2003.

LANDOWSKI, Eric. Presenças do Outro: ensaios de sociossemiótica. Trad. Mary Amazonas Leite de Barros. São Paulo: Perspectiva, 2002.

MOSIONIER, Beatrice Culleton. In Search of April Raintree. Critical Edition edited by Cheryl Suzack. Winnipeg (Canada): Portage \& Main Press, 1999.

MOSIONIER, Beatrice Culleton. The Special Time. In: MOSIONIER, Beatrice Culleton. In Search of April Raintree. Critical Edition edited by Cheryl Suzack. Winnipeg (Canada): Portage \& Main Press, 1999b.

MUNANGA, Kabengele. Rediscutindo a mestiçagem no Brasil: identidade nacional versus identidade negra. Belo Horizonte: Autêntica, 2006.

PATERSON, Janet. Figures de l'Autre dans le roman québécois. Montréal: Nota Bene, 2004.

RIBEIRO, João Ubaldo. Viva o povo brasileiro. O Estado de S. Paulo, São Paulo, 24 abr. 2005. Caderno 2 / Cultura, p. D3.

ROTH, Philip. A marca humana. Trad. Paulo Henriques Brito. São Paulo: Companhia das Letras, 2002.

SANTOS, Gislene Aparecida. A invenção do ser negro (um percurso das idéias que naturalizaram a inferioridade dos negros). São Paulo: Educ/Fapesp; Rio de Janeiro: Pallas, 2005.

THÉRIEN, Gilles. Le Métis comme horizon de la disparition. In: MARIMOUTOU, Jean-Claude Carpanin; RACAULT, Jean-Michel (Ed.). Métissages. Littérature-Histoire. Paris: L'Harmattan, 1992. v. 1. p. 119-130.

VELOSO, Caetano. Orpheus, rising from caricature. The New York Times, New York, 20, Aug. 2000. Arts and Leisure, Section 2, p. 1. 